\title{
Primeiro Registro de Afídeos (Hemiptera: Aphidoidea) em Carambola (Averrhoa carambola L.) no Brasil
}

\author{
Suzan Beatriz Zambon da Cunha ${ }^{\bowtie}$ Carlos Roberto Sousa e Silva
}

Universidade Federal de São Carlos - UFSCar, e-mail: suzanbio@yahoo.com.br (Autor para correspondência ${ }^{\bowtie}$ ), dcrs@ufscar.br.

\section{EntomoBrasilis 9 (3): 207-208 (2016)}

Resumo. A carambola (Averrhoa carambola L.) árvore de origem Asiática foi introduzida no Brasil em 1817, desde então vem aumentando sua área de cultivo no país. A planta é atacada por poucos insetos como as moscas e percevejos. Este trabalho relata a presença de Aphis gossypii Glover em A. carambola pela primeira vez no Brasil.

Palavras-chave: Aphididae; Aphis gossypii; Inseto; Praga; Oxalidaceae.

\section{First Record of Aphids (Hemiptera: Aphididae) on Starfruit (Averrhoa carambola L.) in Brazil}

Abstract. The starfruit (Averrhoa carambola L.) has origin Asiatic and was introduced in Brazil in 1817, since then has increased its cultivation area in the country. The plant is attacked by few insects like flies and bugs. This work reports the presence of Aphis gossypii Glover on A. carambola for the first time in Brazil.

Keywords: Aphididae; Aphis gossypii; Insect; Pest; Oxalidaceae.

\section{A}

carambola (Averrhoa carambola L.) (Oxalidales: Oxalidaceae) é uma árvore frutífera de origem asiática. Segundo Woobson et al. (1980) a família Oxalidaceae engloba, aproximadamente, 950 espécies, distribuídas em 6 gêneros: Dapania e Sarcotheca ocorrendo no velho mundo, Hypseocharis endêmica da região Andina, Oxalis considerada cosmopolita e Biophytum e Averrhoa ocorrendo em regiões tropicais.

A carambola foi introduzida no Brasil em 1817, e atualmente o país é um dos principais produtores da fruta no mundo (NATALE et al. 2008). Além do consumo in natura os frutos e também as folhas das plantas são muito utilizados por apresentarem propriedades medicinais (LORENZI \& MATOS 2008).

A cultura é alvo de poucos insetos nos quais se destacam as moscas das frutas Ceratitis capitata Wied e Anastrepha fraterculus Wied (Diptera: Tephritidae) e os percevejos Leptoglossus stigma Herbst e Leptoglossus zonatus (Dallas) (Hemiptera: Coreidae) ambos causando danos diretos nos frutos (GAllo et al. 2000; Pires et al. 2011).

Os únicos relatos de afídeos em Averrhoa foram feitos por PeÑa \& Duncan (1999) que mencionam a ocorrência de Toxoptera aurantii (Boyer de Fonscolombe) em cultivares de carambola na Flórida e BLACKMAM \& EASTOP (2016) que mencionam a ocorrência de T. aurantii e Aphis gossypii Glover (Hemiptera: Aphididae) em A. carambola e Averrhoa bilimbi L., sem informação da localidade.

No presente trabalho, ninfas e adultos de A. gossypii foram coletados diretamente nas inflorescências, pedúnculos, flores e botões florais de $A$. carambola (Figura 1), em março de 2016 , em São Carlos, São Paulo, S 21 ${ }^{\circ} 54^{\prime} 39.00 ”$, W 047 48' 02.47”. Observou-se também, junto as colônias, a presença de sirfídeos (Diptera: Syrphidae) e coccinelídeos (Coleoptara: Coccinellidae), inimigos naturais de afídeos.

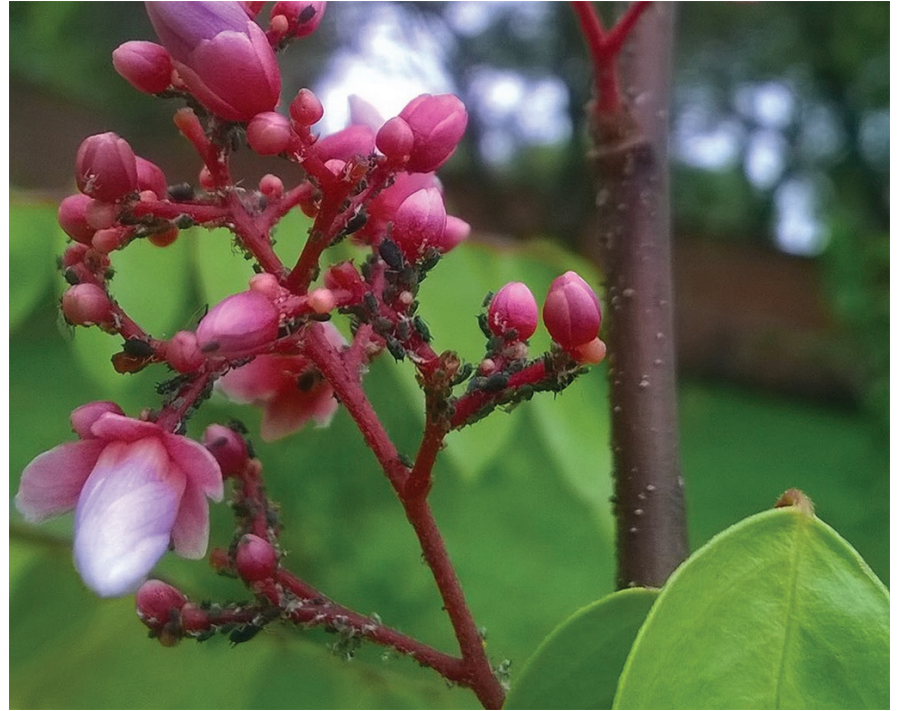

Figura 1. Uma das inflorescências de carambola (Averrhoa carambola L.) infestadas com ninfas e adultos do afídeo A. gossypii no município de São Carlos, SP. (Foto: Cunha, S.B.Z).

A espécie A. gossypii é polífaga e cosmopolita, tendo sido relatada pela primeira vez no Brasil na década de 20 (Moreira 1925). É vetora de diversos vírus aos seus hospedeiros, sendo esta característica a causa mais grave das consequências dos seus ataques. São conhecidos cerca de 50 vírus que $A$. gossypii pode veicular às plantas (BLACKMAN \& EASTOP 2016). Há registros do afídeo atacando diversas plantas de importância agrícola tais como algodão, batata, berinjela, café, caju, citros, ervilha, feijão, jiló, pêra, pepino, pimentão, tomate e diversas outras plantas ornamentais. SOUSA-SiLvA \& ILHARCo (1995) relacionam este afídeo a mais de 67 hospedeiros diferentes no Brasil.

Este é o primeiro registro de A. gossypii em A. carambola, no Brasil, e reforça a alta polifagia desta espécie de afídeo. 


\section{AGRADECIMENTOS}

Agradecemos ao Conselho Nacional de Desenvolvimento Científico e Tecnológico (CNPq) pelo apoio financeiro.

\section{REFERÊNCIAS}

Blackman, R.L. \& V.F. Eastop, 2016. Aphids on the world's plants. An identification and information guide. Disponível em: <http://www.aphidsonworldsplants.info $>$. [Acesso em: o8.iii.2016].

Gallo, D., O. Nakano, S. Silveira R.L.P. Carvalho, G.C. Batista, E. Berti Filho, J.R.P. Parra, R.A. Zucchi, S.B. Alves \& J.D. Vendramim, 2000. Manual de entomologia agrícola, pragas das plantas e seu controle. Ed. Agronômica Ceres, 920 p.

Lorenzi, H. \& F.J.A. Matos, 2008. Plantas medicinais no Brasil: nativas e exóticas, $2^{\mathrm{a}}$ ed., Instituto Plantarum, $544 \mathrm{p}$.

Moreira, C., 1925. Pulgões do Brasil. Boletim do Ministério da Agricultura Industria e Comércio. Instituto Biológico de Defesa agrícola. RJ, 2: 34 p.

Natale, W., R.D.M. Prado, D.E. Rozane, L.M. Romualdo, H.A.D. Souza, \& A. Hernandes, 2008. Resposta da caramboleira à calagem. Revista Brasileira de Fruticultura, 30:1136-1145. doi: http://dx.doi.org/10.1590/S0100-29452008000400048.

Peña, J.E. \& R. Duncan, 1999. Seasonality and control of arthropods on carambola cultivars in Southern florida. Florida State Horticultura Society, 112: 210-212.

Pires, E.M., S.M. Bonaldo, J.A.M. Ferreira, M.A. Soares \& S. Candan, 2011. New Record of Leptoglossus zonatus (Dallas) (Heteroptera: Coreidae) Attacking Starfruit (Averrhoa carambola L.) in Sinop, Mato Grosso, Brazil. EntomoBrasilis, 4: 33-35. doi: http://dx.doi.org/10.12741/ebrasilis.v4i1.114.

Sousa-Silva, C.R. \& F.A. Ilharco, 1995. Afídeos do Brasil e suas plantas hospedeiras (lista preliminar). Edufscar, $85 \mathrm{p}$.

Woodson, R.E., R.W. Schery \& A. Lourteig, 1980. Flora of Panamá. Part IV. Family 84 Oxalidaceae. Annals of the Missouri Botanical Garden, 67: 823-850. doi: http://dx.doi.org/10.2307/2398959.

\section{Recebido em: 30.iii.2016}

Aceito em: 13.ix.2016

\section{Como citar este artigo:}

Cunha, S.B.Z. \& C.R. Sousa e Silva, 2016. Primeiro Registro de Afídeos (Hemiptera: Aphidoidea) em Carambola (Averrhoa carambola L.) no Brasil. EntomoBrasilis, 9 (3): 207-208.

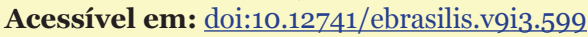
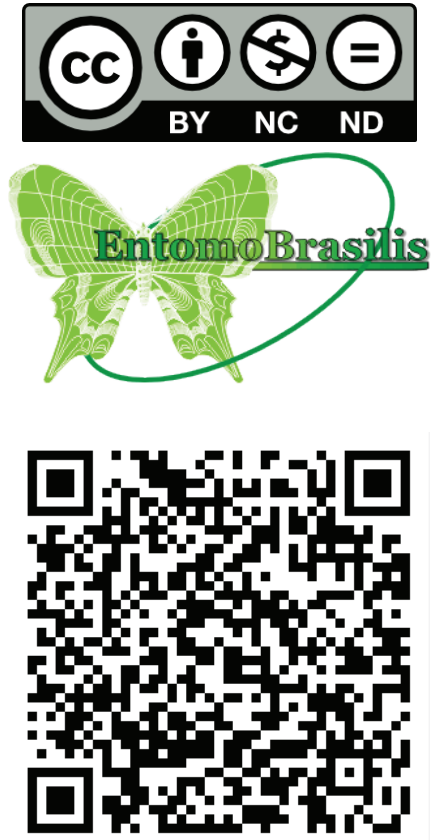